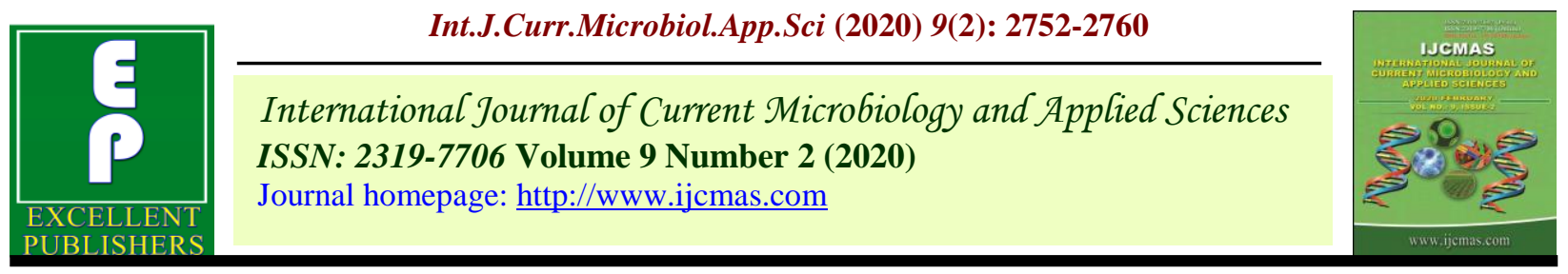

Original Research Article

https://doi.org/10.20546/ijcmas.2020.902.313

\title{
Assessment of Genetic Diversity and to Study the Relationship in Selected Green Gram Germplasm by ISSR Marker
}

\author{
S. S. Mangave ${ }^{1 *}$, N. B. Gokhale ${ }^{1}$, C. B. Kuchekar ${ }^{2}$, S. V. Sawardekar ${ }^{1}$ and J. P. Devmore ${ }^{3}$ \\ ${ }^{1}$ Plant Biotechnology Centre, College of Agriculture, D.B.S.K.K.V. Dapoli, India \\ ${ }^{2}$ J.B. Krishna College of Agriculture, RethareBk, India \\ ${ }^{3}$ DepartmentofA griculturalBotany, College of Agriculture, D.B.S.K.K.V. Dapoli, India \\ *Corresponding author
}

\begin{tabular}{|l|}
\hline Ke y w or d s \\
ISSR, Green \\
gram,Vignaradiata, \\
Molecular marker, \\
genetic diversity.
\end{tabular}

\section{A B S T R A C T}

The molecular marker technology has a great potential for assessing genetic diversity and relationship among the selected varieties. In the present study 52 germplasms of green gram showing distinct morphological differences were screened using 15 ISSR markers. The DNA was extracted from the green leaf samples collected. Modification in extraction procedure resulted into better and clear banding pattern when subjected to PCR analysis. Modification in PCR parameters like PCR master mixture and thermo profile showed clear and specific banding pattern. The green gram DNA showed better amplification with 15 ISSR primers. Total 2721 bands were amplified and out of which 2671 were polymorphic which showed $92.23 \%$ polymorphism. The primer UBC-814 do not showed polymorphism. The size of amplified fragment ranged from $300 \mathrm{bp}$ to $2000 \mathrm{bp}$. The PIC value ranges from 0.00 to 0.87 and average polymorphic information content is 0.75 . It indicates that ISSR markers have a great potential to show the polymorphism among the green gram germplasms. The data were used to generate pair-wise matrix based on the Jaccard's Similarity co-efficient. The genetic distance was calculated on the basis of pooled data and the dendrogram was constructed. The similarity co-efficient ranged from 0.093 to 0.596 indicating the distinctness and similarities of these germplasms.

\section{Introduction}

Green gram (Vigna radiata) also known as mungbean belongs to the family Fabaceae (Leguminoceae). It is a self-pollinated crop having genome size $579 \mathrm{Mbp}$ and is diploid (2n) with 22 chromosomes (Arumuganathan and Earle, 1991). It has strategic position in
Southeast Asian countries for nutritional security and as a sustainable crop.

It is a fast growing crop with a short life span, photo-insensitive and has a dense crop canopy, these qualities gives it a special significance in crop intensification, diversification and conservation of natural 
resources as well as sustainability of production system. Green gram is rich in easily digestible good quality protein $(25.9 \%)$ and lysine $(504 \mathrm{mg} / \mathrm{g})$ for both human and animals (Saini et al., 2010), Mungbean contains $51 \%$ carbohydrate, $24-26 \%$ protein, $4 \%$ mineral and 3\% vitamins. The major constraints in achieving high yield of this crop are lack of genetic variability, poor harvesting index and susceptibility to biotic and abiotic stresses. The major factor out of these remains the lack of genetic variability and non-availability of suitable ideotypes for various cropping plans (Singh et al., 2013).

Mungbean is cultivated in tropical, subtropical and temperate zones of Asia including Bangladesh, India, Pakistan, Myanmar, Indonesia, Philippines, Sri Lanka, Nepal, China, Korea and Japan. India is the world's largest producer as well as consumer of the green gram. It produces about 1.5 to 2.0 million tonnes of mung annually from about 3 to 4 million ha of area with an average productivity of $500 \mathrm{~kg}$ per ha. Green gram output accounts for about $10-12 \%$ of total pulse production in the country. (www.commoditiescontrol.com) The area in Maharashtra under mung bean is 4.48 lakh ha while production is 3.7 lakh tones and average yield $552.98 \mathrm{~kg} / \mathrm{ha}$ during 2014 2015.

The efficiency and effectiveness of conventional breeding can be significantly improved by using molecular markers. Genetic variability and divergence is an important tool for any breeding programme.

Considering the potentials of the DNA marker based genetic diversity analysis for evolving systematic breeding strategies. Marker analysis helps to understand the genetic makeup of the accessions and also make it possible to analyze the global organization of genetic diversity within a species. Several statistical techniques are available for the analysis of genetic diversity using DNA fingerprinting data (Prabhu et al., 2013). Assessment of genetic diversity using DNA markers is one of the key tools of crop improvement and germplasm conservation. Several reports are available assessing the genetic diversity in green gram using DNA based molecular markers namely ISSR (Dellaporta et al., 1983) and RAPD (Fakrudin et al., 2004, Salimath et al., 1995).

ISSR markers are useful in detecting polymorphism among accessions by generating a large number of markers that target multiple microsatellite loci distributed across the genome (Nath et al., 2017).

Although the germplasm collection from India is very large, much diversity has not been reported in morphological characters. Therefore, there is an urgent need to identify genetic divergence based on morphomolecular basis for utilization in breeding programmes.

There are numerous techniques available for assessing the genetic variability and relatedness among crop germplasm. Till now very little efforts have been made to assess the genetic variability among green gram genotypes from Indian sub-continent at molecular level.

Thus, the present study was undertaken with the objective to analyze the genetic variability among the germplasm of green gram through ISSR marker.

\section{Materials and Methods}

In the present investigation 52germplasm of mungbean obtained from Department of Agriculture Botany, Dr. Balasaheb Sawant Konkan Krishi Vidyapeeth, Dapoli. The list of germplasm are given in Table 1. 


\section{Extraction of genomic DNA}

\section{Plant material}

Total 52germplasm of green gram were sown in the pots and kept in greenhouse. The leaf samples were collected from 10 days old seedlings for the extraction of genomic DNA.

\section{DNA extraction}

The DNA was isolated by following the protocol of Doyle and Doyle (1990) i.e. Rapid method with slight modifications of buffer composition and concentration. The young newly emerged leaves were collected and sterilized with $70 \%$ ethanol to avoid the contamination. RNA was removed by RNase treatment and proteins were removed by Proteinase $\mathrm{K}$ treatment. Concentration of DNA in the sample was determined by agarose gel electrophoresis with uncut lambda DNA on 0.8 per cent agarose gel and by comparison of the intensity of band staining with ethidium bromide.

\section{DNA Amplification}

15 ISSR primers composed wholly of defined, short tandem repeat sequences with anchor, and representing different microsatellites (di and tri-repeats) have been used as generic primers in PCR amplification of inter simple sequence repeat regions as per the method of Adawy et al., (2002).A PCR protocol was standardised for all ISSR markers. Each $20 \mu \mathrm{l}$ PCR contained $25 \mathrm{ng}$ template DNA, $2.5 \mu \mathrm{l}$ of $10 \times$ PCR buffer, $0.5 \mu$ lof $15 \mathrm{mM} \mathrm{MgCl} 2,1 \mu 1$ of $10 \mathrm{mMdNTPs}$ (Bangalore Genei Pvt. Ltd., Bangalore, India), 10 pmol of each ISSR (BioresourcenBiotech Pvt. Ltd., Pune, India) and 3.0 units of Taq polymerase (Bangalore Genei Pvt. Ltd.). Thermal profiles were standardised for each ISSR primer pair (i.e. marker) based on its melting temperature using a Eppendorf, Master cycler gradient supplied by Eppendorf gradient, 2231, Hamburg Germany was used for cyclic amplification of DNA. The standard annealing temperatures of all ISSR primers are given in Table 2.

The PCR-amplified products were separated by electrophoresis in $2 \%(\mathrm{w} / \mathrm{v})$ agarose gels at $80 \mathrm{~V}$. The gels were stained with $10 \mathrm{mg} \mathrm{ml}-1$ ethidium bromide and visualised under UV light using a Fire Reader gel documentation system (Uvitec Ltd., Cambridge, UK) and the data were stored for further analysis.

\section{Data analysis}

ISSR markers across the 52germplasm were scored for their presence (1) or absence (0) of bands for each primer. The binary data so generated was used to estimate the levels of polymorphism by dividing the number of polymorphic bands by the total number of scored bands. Jaccard's similarity coefficients for each pairwise comparison between germplasm were calculated and similarity co-efficient matrix was generated. This matrix was subjected to Unweighted Pair Group Method for Arithmetic Average analysis (UPGMA) to construct a dendrogram. The similarity co-efficient analysis and dendrogram construction were carried out by using MVSP-A Multivariate Statistical Package-5785 (Version 3.1).

Distance matrix and dendrogram was constructed based on diversity coefficient generated from pooled data by using unweighted pair group method of arithmetic means (UPGMA), a computer programme for distance estimation.

\section{Results and Discussion}

The primer wise amplification detail of the genomic DNA of 52 green gram germplasm while, per cent polymorphism across the 15 
ISSR primers are presented in the Table 8 . The total 2637scorable DNA fragments were produced and among them 2533 DNA fragments were found to be polymorphic in the green gram germplasm. The maximum number of polymorphic fragments were found to be 232 from primer UBC- 811 followed by 212 from primer UBC-885, while the minimum number of polymorphic fragments produced by the primer UBC-814 was 0 . Average number of polymorphic bands observed per primer were 168.86.

The range of percentage polymorphism across the 15 primers among the 52 germplasm of green gram found to be 0 to 100 per cent and average percentage polymorphism found to be 92.11 per cent. The ISSR profile generated by each primer was analyzed using standard DNA marker (1353bp) $\Phi$ x 174/Hae III digest (100-1300 bp)and compared with their respective banding pattern. Average size ranged from $280 \mathrm{bp}$ to $1646.66 \mathrm{bp}$. The maximum polymorphic information content produced by the primer UBC-857 was 0.85 , followed by the primers UBC -807 , UBC 834 and UBC -885 was 0.84 . The minimum polymorphic information content was produced by the primer UBC-814 was 0.00 .

Average polymorphic information content was 0.75 among the all 52germplasms of green gram. Similarity co-efficient ranged from 0.596 (between germplasm CNG-5 and KSP-3) to 0.093 (between germplasm KARJAT LO and AVMV-1681) indicated the distinctness of these germplasm. The cluster analysis band on the similarity co-efficient clearly distinguished all the 52 germplasm into two groups. The first cluster further subdivided into two subclasses. The first sub class of the first cluster containing 28germplasm i.e.DGG-03, PUSA-1477, ML2333, TARM-2, PKV Green gold, DGG-05, HVM-27, AKM-8802, KARJAT LO, ML2056, NVL-641, Sataya, GM-1102, Basanti,
MH-934, AKM-1210, IPM-990108, RMG1030, Lanja local, C0GG-1010, PM-09-11, NDMK-1301， VGG-05006, DPLM-26, PUSA-1472, TARM-1, PKV-AKM-0 and BM-4, while the second sub class consists of 8germplasm i.e.IPM-05-07, MH-810, PM1012, SGS-26, AVMV-1696, V2 2709, Havsho and AVMV-1684.

The second cluster further subdivided into two subclasses. The first sub class of the second cluster containing 14 germplasm i.e VC389OA, AVMV-1695, MN-94, AVMV1693, AVMV-1698, AVMV-9689, V-2802, AVMV-1677, AVMV-16101, AVMV-1681, AVMV-1682, VC93HH1, CNG-5 and KPS-3, while the second sub class consists of 2germplasmi.eKPS-1 and AVMV-1688. CNG-5 and KSP-3 grouped together with maximum similarity co-efficient (0.596) followed by germplasm KARJAT LO and AVMV-1681 with minimum similarity coefficient (0.093).

\section{Discussion}

ISSR markers are of great significance in interpreting polymorphism. ISSR primers do not require DNA sequence information for designing primers and they reveal variation at several loci simultaneously, thus constituting a multi locus marker system. ISSR approach is an improvement over RAPD which employs more stringent conditions with longer chain length PCR primers and higher annealing temperature.

Unlike AFLPs and SSRs, ISSRs are easier to handle and cost-effective as they can be resolved on agarose gels (Archak et al., 2003). In this study, we have assessed the utility of variable ISSR markers to unique fingerprint and characterize the diversity present in 52germplasm in green gram.52 germplasm are utilized for ISSR analysis with 15 random primers and all of them gave 
scorable DNA bands and out of the 14 random primers revealed polymorphism. Similar results were reported by Singh et al., (2011) who carried out the investigation to study the genetic diversity using nine AFLP and 22 ISSR primers in 30 green gram genotypes. All of nine AFLP and 22 ISSR primers showed polymorphism used for molecular analysis, 31 primers showed polymorphism among 30 green gram genotypes.

Table.1 Details of germplasm used in the study.

\begin{tabular}{|c|c|c|c|}
\hline Sr. No. & Name of Germplasm & Sr. No. & Name of Germplasm \\
\hline 1. & AVMV-1688 & 27. & C0GG-1010 \\
\hline 2. & KPS-1 & 28. & Lanja local \\
\hline 3. & KPS-3 & 29. & IPM-990108 \\
\hline 4. & CNG-5 & 30. & RMG-1030 \\
\hline 5. & AVMV-1681 & 31. & AKM-1210 \\
\hline 6. & VC389OA & 32. & MH-934 \\
\hline 7. & VC93HH1 & 33. & Basanti \\
\hline 8. & AVMV-16101 & 34. & GM-1102 \\
\hline 9. & AVMV-1684 & 35. & Sataya \\
\hline 10. & AVMV-1682 & 36. & SGS-26 \\
\hline 11. & AVMV-1677 & 37. & AKM-8802 \\
\hline 12. & V-2802 & 38. & DGG-05 \\
\hline 13. & AVMV-9689 & 39. & HVM-27 \\
\hline 14. & V2 2709 & 40. & PM-1012 \\
\hline 15. & MN-94 & 41. & PKV Green gold \\
\hline 16. & Havsho & 42. & TARM-2 \\
\hline 17. & AVMV-1695 & 43. & PUSA-1477 \\
\hline 18. & AVMV-1696 & 44. & ML-2333 \\
\hline 19. & AVMV-1698 & 45. & NVL-641 \\
\hline 20. & AVMV-1693 & 46. & ML-2056 \\
\hline 21. & BM-4 & 47. & PUSA-1472 \\
\hline 22. & MH-810 & 48. & TARM-1 \\
\hline 23. & IPM-05-07 & 49. & PKV-AKM-0 \\
\hline 24. & VGG-05006 & 50. & DGG-03 \\
\hline 25. & NDMK-1301 & 51. & KARJAT LO \\
\hline 26. & PM-09-11 & 52. & DPLM-26 \\
\hline
\end{tabular}


The primers produced high degree of polymorphism with an average of 92.11 per cent. Average 175.8 bands per primer were amplified. Among the 15 generic primers 13 primers UBC - 807, UBC - 811, UBC - 834, $\mathrm{UBC}-841$, UBC - 844, UBC - 854, UBC 857, UBC - 874, UBC $-876, \mathrm{UBC}-881$, UBC - 885, UBC - 886 and UBC 891revealed 100 per cent polymorphism, primer UBC-811 shows 81.69 per cent polymorphism and primer UBC-814 doesn't show polymorphism.

The percentage of polymorphism across the green gram genotypes ranged from 81.69-100 per cent. SaiRekha et al., (2015) recorded similar results in analysis of genetic diversity of 12 mung genotypes with 18 ISSR primers percentage of polymorphism ranged from 50100 per cent among 12 genotypes. The genetic distance was computed considering the 52 germplasm from the pooled data. The overall range of the similarity among 52 germplasm of green gram was found to be very wide ranging from 0.093to 0.596which indicates there was high variability among the green gram cultivars under study. Based on the similarity matrix and clustering pattern, the germplasm CNG-5 and KSP-3 were found to have maximum similarity coefficient 0.596 , While, the lowest similarity coefficient 0.093 were observed in between the germplasm KARJAT LO and AVMV-1681 which was suggesting a large differentiation in the germplasm of green gram. Similar observations were also recorded by Singh et al., (2012) while carried out the study on assessment of genetic relatedness among mung mutant linesusing ISSR Markers. In this study molecular markers revealed similarity index among mutated lines ranged from 0.88 to 0.99 .

Table.2 List of ISSR primers with their sequence

\begin{tabular}{|c|c|c|c|c|}
\hline \multirow[t]{2}{*}{$\begin{array}{l}\text { Sr. } \\
\text { No. }\end{array}$} & \multirow[t]{2}{*}{ Primer } & Primer sequence & $\begin{array}{c}\text { GC } \\
\text { Content }\end{array}$ & Tm $^{0}$ Value \\
\hline & & $\left(5^{\prime}-3^{\prime}\right)$ & $(\%)$ & $\left({ }^{0} \mathrm{C}\right)$ \\
\hline 1. & UBC-807 & AGAGAGAGAGAGAGAGT & 47.1 & 45.0 \\
\hline 2. & UBC 811 & GAG AGA GAG AGA GAG AC & 52.9 & 43.3 \\
\hline 3. & UBC 814 & СТС ТСТ СТС ТСТ СТС ТА & 47.1 & 41.4 \\
\hline 4. & UBC-818 & CACACACACACACACAG & 52.9 & 52.1 \\
\hline 5. & UBC-834 & AGAGAGAGAGAGAGAGT & 50.0 & 49.8 \\
\hline 6. & UBC-841 & GAGAGAGAGAGAGAGAC & 55.5 & 45.7 \\
\hline 7. & UBC-844 & CTC TCT CTC TCT CTC TRC & 55.5 & 39.4 \\
\hline 8. & UBC-854 & TCTCTCTCTCTCTCTCRG & 55.5 & 51.1 \\
\hline 9. & UBC-857 & ACACACACACACACACCG & 55.5 & 57.1 \\
\hline 10. & UBC-874 & ССС ТСС СТС ССТ СССТ & 75.0 & 33.0 \\
\hline 11. & UBC-876 & GAT AGA TAG ACA GAC A & 37.5 & 36.4 \\
\hline 12. & UBC-881 & GGG TGG GGT GGG GTG & 66.6 & 66.5 \\
\hline 13. & UBC-885 & HBHAGAGAGAGAGAGAG & 52.9 & 41.7 \\
\hline 14. & UBC-886 & VDVCTCTCTCTCTCTCT & 52.9 & 36.9 \\
\hline 15. & UBC-891 & AGATGTGTGTGTGTGTG & 47.1 & 51.8 \\
\hline $\begin{array}{l}\mathrm{C} / \mathrm{G} / \\
\mathrm{A} / \mathrm{C} / \\
\mathrm{COR}\end{array}$ & $\begin{array}{ll}\text { e. } \operatorname{not} A) & \text { H } \\
\text { (e. } \operatorname{not} T) & \mathrm{I} \\
\text { not } A, G) R\end{array}$ & $\begin{array}{l}\text { /T) (i.e. } \operatorname{not} \mathrm{G}) \\
/ \mathrm{T})(\text { i.e. } \operatorname{not} \mathrm{C}) \\
\text { G(i.e. } \operatorname{not} \mathrm{C}, \mathrm{T})\end{array}$ & & \\
\hline
\end{tabular}



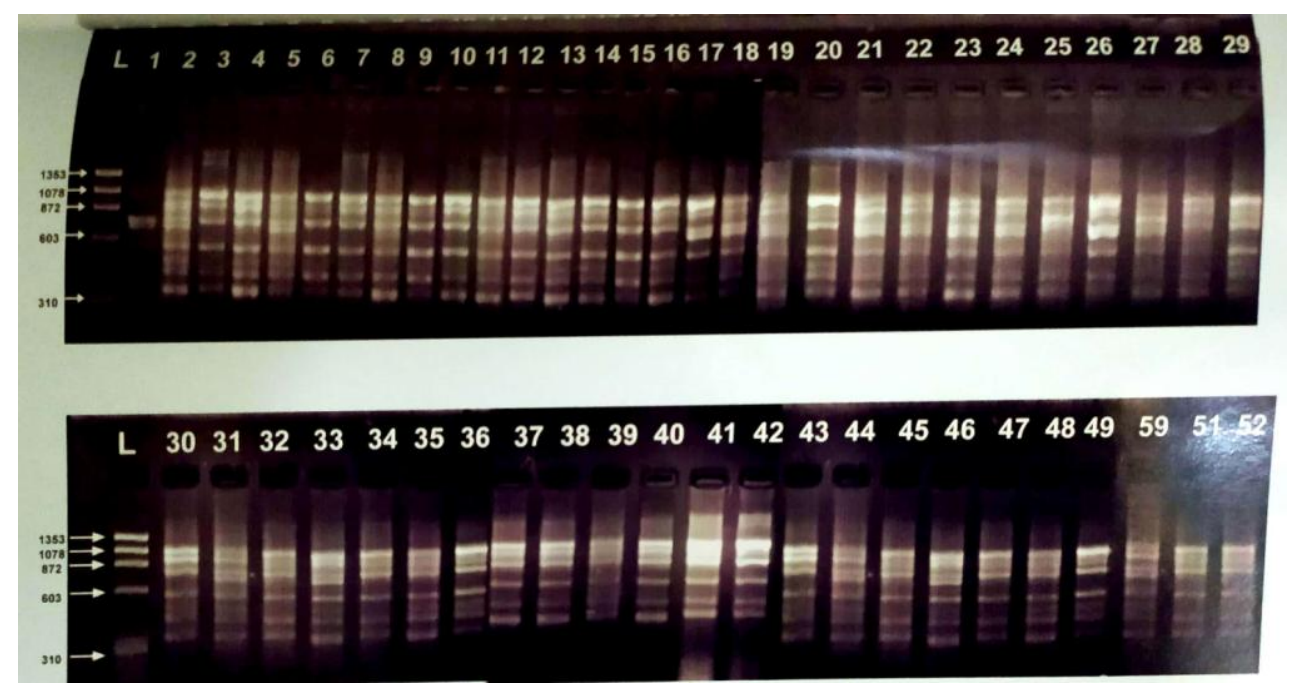

Fig.1 Gel photopgraph of ISSR profile of greent gramgermplasm produced by primer UBC-811

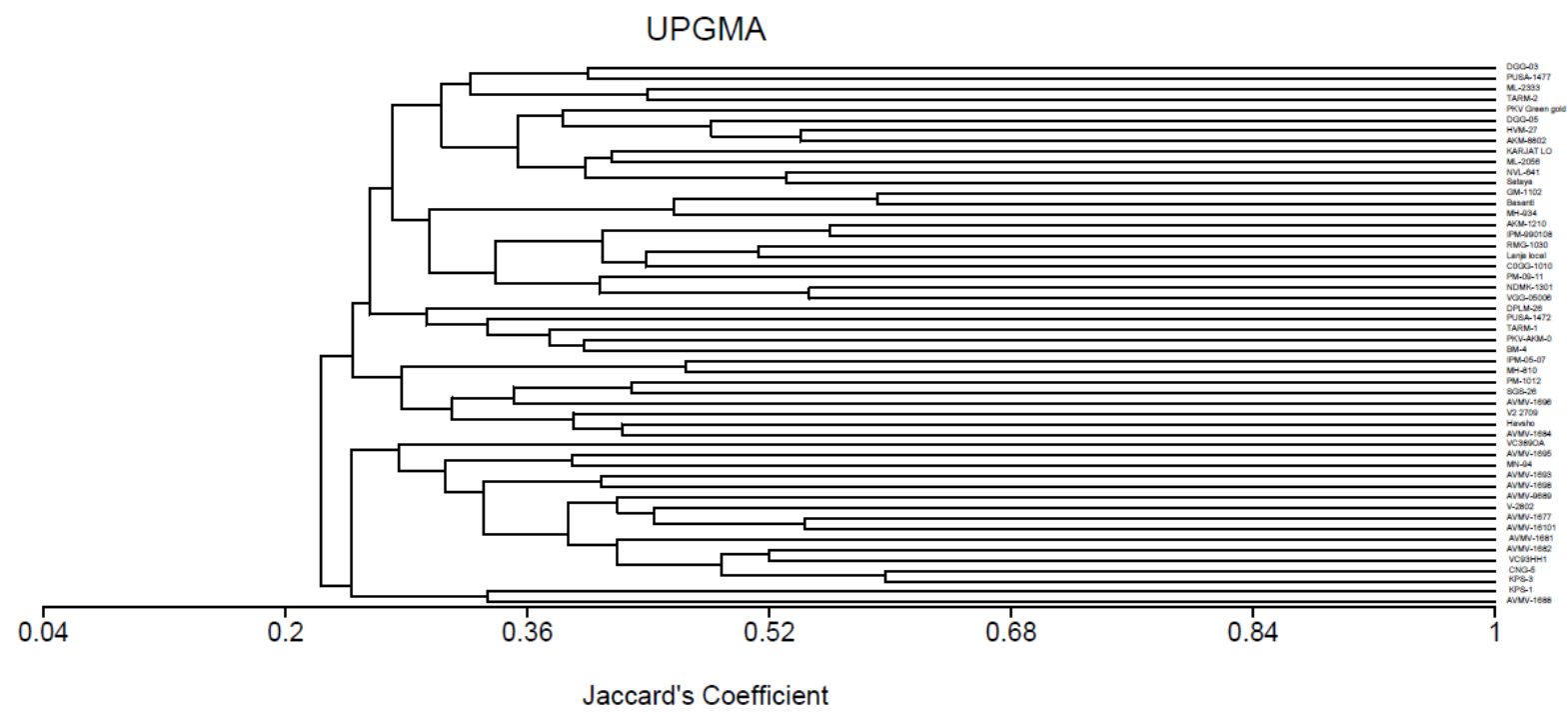

Fig.2 Cluster

The Polymorphism Information Content (PIC) value calculated for the 15 ISSR primers. In the present study the maximum PIC information produced by the primer UBC - 857 (0.85) while the minimum PIC value was given by the primer UBC-814 (0.00) the average PIC value obtained for each primer was 0.75 . These results are conformation with Kaur et al., (2016) that is the PIC value was ranged from 0.07 to 0.35 with an average value of 0.208 across 23 green gram genotypes. The cluster analysis was carried out based on the ISSR profile. The results based on the ISSR profile broadly grouped the 52 green gram germplasm into two main clusters (I and II). The first cluster (I) was formed by the two subclasses. The first sub class of the first cluster containing 28 germplasm while the second sub class containing of 8 germplasm. The second cluster(II) further subdivided in to two subclasses. The first sub class of the second cluster containing 14 germplasm while the second sub class consists of 2 germplasm. Similar results have been found by Kaur et $a l$. , (2016) for green gram accessions in which 
the cluster one contain 20 genotypes variety and cluster two Contain three genotypes respectivelybased on ISSR analysis. This study could be used to identify the diverse genotypes like KPS-1, AVMV-1688 and their use in hybridization programme of green gram. The genetic diversity in this study might be useful in future strategies for development of desired genotypes.

\section{References}

AnamikaNath, S.R. Maloo, B.L. Meena, A. Gangarani Devi and SheetalTak (2017) Assessment of Genetic Diversity Using ISSR Markers in Green Gram [Vigna radiata (L.)Wilczek]. International Journal of Current Microbiology and Applied Sciences ISSN: 2319-7706 Volume 6 Number 5 (2017) pp. 11501158

Anonymous (2014-2015). www.commodities control.com

Anonymous (2015-2016). Directorate of Economics and Statistics, Ministry of Agriculture.

Archak S, Gaikwad AB, Gautam D, Rao EVVB, Swamy KRM and Karihaloo.(2003).Comparative assessment of DNA fingerprinting techniques (RAPD, ISSR and AFLP) for genetic analysis of cashew (Anacardium occidentale L.) accessions of India. Genome46: 362-369.

Arumuganathan, K. and Earle, E.D. (1991).Nuclear DNA content of some important plant species.Plant Molecular Biology Report ,9: 208-218.

Dellaporta S. L., Wood J., Hick J. B., (1983). A plant DNA mini preparation.Version II.Pl. Mol. Bio.Reporter., 1: 19-21.

Doyle J. J. and Doyle J. L. (1990).Isolation of plant DNA from fresh tissue.Focus.,12: 13-15.

Fakrudin, B., Shashidhar H. E., Kulkarni R. S., Hittalmani S., (2004). Genetic diversity assessment of finger millet, Eleusinecoracana (Gaertn.), germplasm through RAPD analysis.PGR Newslett., 138: 50-54.

GunnjeetKaur, Arunabh Joshi, Devendra Jain, Deepak Rajpurohit and DivyaVyas (2016) Assessment of Genetic Diversity in Mungbean Genotypes using ISSR Markers. Vegetos- An International Journal of Plant Research, Vegetos 2016, 29:3 DOI: 10.5958/22294473.2016.00067.7.

K. SaiRekha, D.M. Reddy, B. Ravindra Reddy, K. H. P Reddy, B. V. Bhaskara Reddy (2015) DNA Fingerprinting and Genetic Diversity Analysis Using RAPD, SSR And ISSR Markers In Mungbean (Vignaradiata (L.) Wilczek). IOSR Journal of Agriculture and Veterinary Science (IOSR-JAVS) eISSN: 2319-2380, p-ISSN: 2319-2372. Volume 8, Issue 7 Ver. II (July. 2015), PP 63-68 www.iosrjournals.org.

Prabhu R., Ganesan N. M., (2013). Genetic diversity studies in ragi (Eleusinecoracana(L.) Gaertn.)with SSR and ISSR Markers. Mol. Pl. Breeding.,4(17):141-145.

Renu Singh, Adriaan W. van Heusden and Ram C. Yadav(2011) A comparative genetic diversity analysis in mungbean (Vignaradiata L.) using inter-simple sequence repeat (ISSR) and amplified fragment length polymorphism (AFLP). African Journal of Biotechnology, Vol. 12(47), pp. 6574-6582, 20 November, 2013 DOI: $10.5897 / A J B 11.2882$ ISSN 1684-5315 C2013 Academic Journals http://www.academicjournals.org/AJ.

S K SINGH, SURESH B G, G R LAVANYA, LALIT ARYA, $\mathrm{K}$ V BHAT, Z HUSSAIN and M VERMA (2012) Assessment of genetic variability in mutant lines of greengram (Vignaradiata) using ISSR markers. Indian Journal of Agricultural Sciences 
84 (4): 534-9, April 2014.

Saini, M. Singh, S. Hussain, Z. and Yadav, A. 2010. RAPD analysis in mungbean (Vigna radiata (L.) Wilczek): I. Assessment of genetic diversity. Indian J. Bioteh.9:137-140.

Salimath, S.S., De Oliveira A. C., Godwin I. D., Bennetzen J. L., (1995). Assessment of genome origins and genetic diversity in the genus Eleusine with DNA markers. Genome.,38: 757-763.

Singh, A., Dikshit, H.K., Jain, N., Singh, D. and Yadav, R.N.(2013).Efficiency of SSR,ISSR and RAPD markers in molecular characterization of green gram and other Vigna species. Indian Journal of Biotechnology, 13: 81-88.

\section{How to cite this article:}

Mangave. S. S, N. B. Gokhale, C. B. Kuchekar, S. V. Sawardekar and Devmore. J. P. 2020. Assessment of Genetic Diversity and to Study the Relationship in Selected Green Gram Germplasm by Issr Marker. Int.J.Curr.Microbiol.App.Sci. 9(02): 2752-2760.

doi: https://doi.org/10.20546/ijcmas.2020.902.313 